\title{
EDITORIAL
}

\section{Los desafíos estratégicos para la gestión de la investigación universitaria en la sociedad del conocimiento ${ }^{1}$}

La sociedad del conocimiento está evolucionando a partir del dominio y posicionamiento de las tecnologías de la información y comunicación en los más diversos y amplios campos del quehacer de la comunidad, las organizaciones y las personas. En la nueva sociedad, las tecnologías de información y comunicación se unen en un proceso mayor de convergencia tecnológica, en el que es necesario añadir a la nanotecnología, la biotecnología y las ciencias cognitivas, para configurar-de una manera integrada-, nuevas potencialidades para las relaciones sociales y para el desarrollo humano.

En este contexto, se rompen las barreras tradicionales del espacio y tiempo posibilitándose una incorporación de múltiples actores institucionales o individuales de diversas partes del orbe, en un mundo digital de interacción que progresa y se desarrolla de manera ininterrumpida. A su turno, en la sociedad del conocimiento se está ampliando la esperanza y la calidad de vida de las personas mediante el diseño y aplicación de dispositivos nanotecnológicos que podrán enfrentar algunas de las enfermedades más relevantes con amplias posibilidades de éxito.

Asimismo, la nanobiotecnología unida a las ciencias informáticas proporcionarán elementos para enfrentar los cambios climáticos, el calentamiento global y/o la escasez de alimentos, con mejores oportunidades para la humanidad. No menos importante resulta reconocer que las nuevas tecnología seguirán teniendo efectos sobre el aprendizaje y sobre el desarrollo cognitivo, lo que en complemento con el fortalecimiento y desarrollo creciente de las ciencias cognitivas permite prever que el desarrollo intelectual de las personas llegará a niveles muy superiores a los actuales, avanzando significativamente en el reconocimiento de los potenciales límites del desarrollo humano.

En la actual sociedad, el conocimiento pasa a ser un determinante estructural del progreso y desarrollo de las naciones. Además, a nivel de las organizaciones el conocimiento se transforma en una fuente esencial de ventaja competitiva, toda vez que -precisamente- las organizaciones que tienen un nivel superior de conocimiento, son capaces de coordinar y combinar sus recursos tradicionales en nuevos y distintos caminos, creando innovaciones que tienen un valor diferenciador para la sociedad.

Así las cosas, las universidades tienen un rol preponderante en un entorno de convergencia tecnológica y en la gestión de la investigación, es decir, su creación, uso y difusión constituye un eje fundamental del desarrollo de estas entidades de educación superior.

Ahora bien, la gestión de la investigación en las universidades requiere visualizar un conjunto de aristas -al menos tres- para un cabal cumplimiento de sus expectativas en la sociedad del conocimiento.

La primera arista consiste en reconocer que la investigación es una tarea irrenunciable para una universidad y que no se puede desistir de realizar una función que es consustancial a su condición esencial o natural como entidad de educación superior. Sin investigación no hay universidad posible en la sociedad del conocimiento, aunque -desde luego- pueden existir diferentes aproximaciones institucionales para lograr esta tarea, desde extremos en los que todos los académicos de una universidad realizan investigación hasta otros escenarios en los cuales la docencia es predominante, pero existen nichos específicos en los que se investiga.

1 Proyecto FONDECYT Nº 1140026 
La gestión de la investigación tiene el desafío o imperativo de lograr un equilibrio entre la libertad para pensar e investigar y los resultados requeridos por la institución y la sociedad en un tiempo razonable. Sin libertad de pensamiento y un espacio de libertad para crear e investigar es muy difícil realizar contribuciones significativas al acervo de conocimientos; pero - a su vez- sin resultados académicos relevantes, simplemente no existe sustentabilidad para avanzar en la labor investigativa.

En consecuencia, bajo esta primera arista, la gestión de la investigación en las universidades debe considerar los talentos académicos insertos en la institución y aquellos que se puedan sumar en un horizonte temporal determinado, definiendo modelos plurianuales de asignación de recursos, considerando metas razonables para el sistema nacional e internacional y respetando los tiempos y estándares propios de cada disciplina.

La segunda arista consiste en reconocer que la investigación debe permear hacia la sociedad. Desde luego, hay espacios naturales para la investigación básica y aplicada y -ciertamente- no todas las investigaciones derivarán en desarrollo e innovación. No se puede forzar la naturaleza intrínseca de cada línea de investigación; pero la universidad -como un todo- sí tiene el imperativo de considerar que -al menos- una parte de su trabajo de investigación debe ir como contribución directa a la sociedad y no solo la comunidad científica.

No se puede desconocer que la sociedad -incluyendo las comunidades locales- demanda, cada vez con mayor insistencia, una investigación capaz de resolver los problemas del desarrollo territorial en los diferentes ámbitos y áreas como la salud, la educación, la industria, entre otras equivalentes y propias del desarrollo regional. Las universidades no pueden cerrar sus puertas a estos requerimientos, que además pueden derivarse no solo de los gobiernos regionales o comunitarios, sino que también del sector productivo.

Por consiguiente, bajo esa segunda arista, la gestión de la investigación en las universidades debe considerar una vinculación con el medio vigorosa, junto a la posibilidad de alianzas estratégicas de largo plazo con el sector privado y con los gobiernos regionales o locales, para lo que requiere de equipos de investigación calificados y capaces de satisfacer las exigencias elevadas de actores que trabaja con sentido de urgencia, en ritmos y tiempos que son restrictivos y en un marco de competencia a escala global o-al menos- nacional.

La tercera arista consiste en reconocer que en la sociedad del conocimiento la creación de conocimiento avanzado debe ir de la mano con la formación de capital humano avanzado tanto a nivel de pregrado como postgrado. Se trata de dimensiones esencialmente complementarias y en las cuales es posible generar sinergias valiosas. Naturalmente, la formación de doctorado va de la mano con la formación de investigadores, ya que los estudiantes doctorales - por definición- deben demostrar su capacidad para desarrollar una investigación -en forma autónoma- con resultados relevantes para el estado del arte.

En efecto, las sinergias son susceptibles de alcanzarse tanto en la formación de magíster como doctores, aunque el potencial de sinergias no es exclusiva del nivel de postgrado. Nutrir la formación de pregrado y postgrado con investigación es tan vital como nutrir la investigación con jóvenes deseosos de aprender, con potencial intelectual, y con la preparación suficiente para contribuir a una tarea vital de las universidades.

Por lo tanto, la articulación entre investigación y docencia de pregrado y postgrado no puede soslayarse. Ciertamente, el desafío de la gestión de la investigación en las universidades consiste básicamente en conjugar los talentos, los recursos y las capacidades institucionales, respondiendo con energía intelectual a las demandas y requerimientos de la sociedad del conocimiento.

\author{
Dr. Emilio Rodríguez-Ponce \\ Universidad de Tarapacá \\ Arica, Chile \\ erodriguez@uta.cl
}

